\title{
Frequency and working memory effects in incidental learning of a complex agreement pattern
}

Article

Accepted Version

Creative Commons: Attribution-Noncommercial-No Derivative Works 4.0

Denhovska, N., Serratrice, L. and Payne, J. (2018) Frequency and working memory effects in incidental learning of a complex agreement pattern. Lingua, 207. pp. 49-70. ISSN 00243841 doi: https://doi.org/10.1016/j.lingua.2018.02.009 Available at https://centaur.reading.ac.uk/76938/

It is advisable to refer to the publisher's version if you intend to cite from the work. See Guidance on citing.

Published version at: http://dx.doi.org/10.1016/j.lingua.2018.02.009

To link to this article DOI: http://dx.doi.org/10.1016/j.lingua.2018.02.009

Publisher: Elsevier

All outputs in CentAUR are protected by Intellectual Property Rights law, including copyright law. Copyright and IPR is retained by the creators or other copyright holders. Terms and conditions for use of this material are defined in the End User Agreement.

www.reading.ac.uk/centaur 
Central Archive at the University of Reading

Reading's research outputs online 
1 Frequency and working memory effects in incidental learning of a complex agreement

pattern

3

Abstract

5 Complex grammatical structures have been assumed to be best learned implicitly

6 (Krashen, 1982, 1994; Reber, 1989). However, research to date has failed to support

7 this view, instead finding that explicit training has overarching beneficial effects. The

8 present study attempted to elucidate this issue by examining how type and token

9 frequencies in incidental learning input and individual differences in the learner's working

10 memory (WM) combine to affect the receptive and productive learning of a complex

11 agreement pattern in a novel language. The findings indicated that type frequency

12 significantly enhanced receptive knowledge acquisition even more than explicit

13 instruction. Performance on the productive knowledge retrieval task was poor under all

14 learning conditions but most accurate under the explicit learning condition. WM was not

15 implicated in incidental learning, possibly indicating that all learners experience high

16 cognitive demand imposed by the target structure regardless of variation in WM

17 capacity. 
Keywords: L2 grammar, linguistic complexity, incidental learning, frequency, working

memory

\section{Introduction}

A subject of long-standing debate has been whether a complex grammatical

pattern can be more successfully learned under implicit (Krashen, 1982, 1994;

24 Reber, 1989) rather than explicit learning conditions (Hulstijn \& de Graaff, 1994). To

25 date, extensive second language acquisition (SLA) research has determined that

explicit training/classroom instruction is generally more beneficial than implicit training

27 for learning a complex structure in L2 (DeKeyser, 1995; N. Ellis, 1993; Norris \& Ortega,

28 2000; Robinson, 1996; Spada \& Tomita, 2010). However, it may be that it is the

29 combined effects of multiple factors that trigger successful knowledge acquisition in

30 incidental learning contexts, a facet we currently know little about. Importantly, with

31 regard to considering incidental learning, Hulstijn (2005) highlighted that it is essential to

32 understand the interactions among the following factors rather than studying each factor

33 in isolation: 1) the complexity of the system underlying the data; 2) the frequency with

34 which the linguistic structures are presented to the learners in the input; and 3) learners' 
35 individual differences with respect to knowledge, skills, and information processing ( $p$. 133).

The linguistic complexity of the structure is often associated with cognitive complexity or learning difficulty (DeKeyser, 2005; Housen, 2014; Marsden, Williams, \& Liu, 2013), which is affected in turn by individual differences in cognitive abilities, including working memory (WM) capacity variability (Grey, Williams, \& Rebuschat, 2015; Juffs \& Harrington, 2011; Tagarelli, Ruiz-Hernandez, Vega \& Rebuschat, 2016). In addition, it has been posited that the complexity of a linguistic structure interacts with its input-related properties, such as the frequency of the occurrence of the structure in the input, making it more or less accessible for acquisition (Housen \& Simoens, 2016). Hence, frequency may mediate adult incidental learning by creating a more or a less effective learning context. For L1 acquisition of complex morphologies, type and token frequencies are known to be vital (Tomasello, 2000, 2008). The present study thus attempts to understand the effects of type and token frequencies on adult acquisition of a complex L2 pattern and the extent to which the manipulation of type and token frequencies in the incidental learning condition impacts the effectiveness of learning such a structure. In particular, this paper focuses on the acquisition of a complex noun- 
52 adjective agreement pattern in a richly inflected language (Russian) by adult novice

53 learners (who are speakers of an L1 with a less rich morphology) in terms of

54 comprehension and production modalities. Further, this paper examines how individual

55 differences in learners' WM mediate this acquisition under different learning conditions.

57 adult learner, particularly if the learner's L1 does not share the feature to be acquired in examined the acquisition of inflectional morphology (Brooks, Kempe \& Donachie, 2011;

60 Kempe, Brooks \& Kharkhurin, 2010; Kempe \& McWhinney, 1998), few have devoted

61 attention to its incidental acquisition (Brooks \& Kempe, 2013; Rogers, Revesz, \&

62 Rebuschat, 2015), and to our knowledge, no studies have explored the combined effect of frequency and WM during the incidental learning of such complex systems.

\section{Background}

\subsection{Definition of terminology}



implicit learning is typically understood as a process of acquiring a target structure

70 without intention and awareness that results in the accumulation of implicit knowledge

71 (Williams, 2009). By contrast, explicit learning is a process during which the learner is

72 consciously involved in the processing of the stimulus input. The term incidental

73 learning is used to denote the experimental condition in which the learner is directed to

74 the meaning rather than to the grammatical structure of interest and is not informed

75 regarding any testing to follow (Rebuschat \& Williams, 2012). Accordingly, learning

76 under such conditions may or may not result in implicit knowledge. The present paper

77 does not address the issue of conscious/unconscious knowledge developed under

78 these conditions. Sometimes, the notion of the "implicit learning condition" is used to

79 refer to a similar experimental paradigm (Morgan-Short et al., 2010, 2012). In the

80 present study, we follow Rebuschat and Williams (2012) and adopt the definition of

81 incidental learning as a training condition. In contrast, we use the term explicit learning

82 condition to refer to a condition where knowledge acquisition is fostered by providing

83 metalinguistic information about the target structure (Spada \& Tomita, 2010; Robinson, 84 1996). 

complex structures, frequency and WM. We then present and discuss our investigation of the incidental learning of a number agreement pattern in a novel natural and fusional language (Russian) that simultaneously marks gender and case.

90

\subsection{Acquisition of complex grammatical patterns under incidental learning conditions} Various studies have employed different understandings of complexity, including pedagogical, linguistic and psycholinguistic complexities (Collins, Trofimovich, White et al., 2009; see Spada \& Tomita, 2010 for meta-analysis). Most commonly, however, research has adopted the absolute or the relative approach to defining the complexity of language structure. The present study utilizes the absolute (Dahl, 2004; McWhorter, 2001, 2007) or structural approach (Bulte \& Housen, 2012; Miestamo, 2008; Pallotti, 2015), which asserts that the more parts a system has, the more complex it is. Based on this definition, a morphological pattern similar to the subject of the present study,

101 which has inflectional markers signalling agreement based on number, gender and case, would be considered complex as opposed to a morphological pattern that factors 
in only one of these features. The relative approach (Kusters, 2003), in contrast, defines

104 complexity in terms of processing costs and difficulty for language users, predicting that

105 linguistically complex structures also demand that more cognitive resources be

106 expended by the learner.

108 emphasizes the complexity of the form, such as the number of forms in a paradigm, and

109 suggests - consistent with the taxonomic model of L2 complexity (Bulte \& Housen,

1102012 ) - that morphological systems are more complex in richly inflected languages.

111 Consequently, scholars have noted that features in L2 that are different from the

112 learner's L1 are difficult to learn from input either implicitly or explicitly because

113 morphology is a weak cue during the initial stages of language learning.

114 Conversely, Krashen (1982) introduced the distinction between complex

115 structures that are easy to acquire [implicit] but difficult to learn [via explicit instruction]

116 and simple structures that are easy to learn but difficult to acquire, which led to several

117 experimental studies (de Graaff, 1997; DeKeyser, 1995; Robinson, 1996; Tagarelli,

118 Ruiz-Hernandez, Vega \& Rebuschat, 2016; Van Daele, 2005). Research that directly

119 compared knowledge attainment of different L2 grammar structures (e.g., word order, 
120 plural marking, passives, and gender agreement) generally found similar retention

121 levels under both implicit and explicit conditions (Andringa, De Glopper, \& Hacquebord,

122 2011; de Graaff, 1997; DeKeyser, 1995; Morgan-Short et al., 2010, 2012; Robinson,

123 1996; Williams \& Evans, 1998). Similar findings were obtained by research in classroom

124 settings that employed implicit (meaning-focused) and explicit (form-focused) instruction

125 for learning grammar structures in L2 French that were simple (i.e., negation) and

126 complex (i.e., passive constructions) (Van Daele, 2005). This trend was partially

127 confirmed in more recent research by Tagarelli et al. (2016), who used syntactic

128 structures of different complexity modelled on German word order in a semi-artificial

129 language to study how complexity interacts with implicit/explicit learning conditions.

130 Higher learning effects were found for all structures in the explicit learning condition. Nevertheless, previous research has generally overlooked the role of factors

132 such as frequency that may mediate incidental learning, which may explain why such

133 research has failed to find the benefits of incidental learning over explicit training in

134 acquiring complex structures. The subsequent section outlines the importance of the

135 frequency factor in incidental learning and reviews the experimental literature on the

136 role of frequency in grammatical knowledge acquisition. 
137

138

140

141 input and storing them in memory (Johnstone \& Shanks, 2001; Knowlton \& Squire,

142 1994; Knowlton, Ramus, \& Squire, 1992; Perruchet \& Pacteau, 1990). Many theoretical

143 models - such as the usage-based approach to grammar (Bybee, 1998; Goldberg,

144 2006; Langacker, 1987) and connectionist models of language learning and processing

145 (Christiansen \& Chater, 1999, Elman, 1991; MacWhinney, 1998) - credit frequency with

146 a fundamental role in learning. While assuming that the acquisition of grammar is a

147 piecemeal accumulation of specific constructions and frequency-based abstractions of

148 regularities within them, the usage-based approach distinguishes the different roles of

149 type and token frequencies (Bybee, 1985, 2010; Ellis, 2002, 2006; Hulstijn, 2005;

150 Tomasello, 2000, 2008). Token frequency is believed to play a significant role in

151 strengthening new representations of specific schemas and is important during the

152 initial stages of learning, whereas type frequency has a privileged role in subsequent

153 knowledge abstraction. Although having been extensively studied from the perspective

154 of L1 acquisition and processing (Abbot-Smith, Lieven, \& Tomasello, 2004; Arnon \& 
155 Snider, 2010; Lieven \& Tomasello, 2008; Tomasello, 2003) and greatly emphasized in

156 terms of L2 acquisition (Gass \& Mackey, 2002; Ellis, 2002; Ellis \& Ferreira-Junior,

157 2009), experimental evidence remains limited at present with regard to the effects of

158 type and token frequencies in adult incidental learning of complex morphology. The theoretical motivation for understanding the roles of type and token

160 frequencies in the incidental learning of L2 complex morphology stems from the debate

161 whether the same or different mechanisms underlie L1/L2 acquisition (Abutalebi \&

162 Green, 2008; Perani \& Abutalebi, 2005; Ullman, 2004). If the same mechanisms that

163 guide L1 grammatical development are available in adulthood, then the incidental

164 learning of L2 grammar in post-puberty learners should be promoted by type and token

165 frequencies in a similar manner. An alternative theoretical perspective stipulating that L2

166 grammar learning is fundamentally different from L1 (Bley-Vroman, 1989) and largely

167 relies on declarative rather than procedural mechanisms (Ullman, 2004) also relies on

168 the importance of frequency. Pursuant to this approach, frequency may be the trigger

169 that initiates the shift towards the recruitment of procedural mechanisms by providing

170 more experience (practice) with language (Ullman, 2001). With regard to the acquisition

171 of complex L2 structures, some approaches propose developmental timing as a function 
172 of the structure complexity, positing that it requires more time to master complex

173 features (Pienemann, 1989; Collins, Trofimovich, White, Cardozo, \& Horst, 2009). This

174 view implies that frequency might be one of the tools that bridges the gap between the

175 emergence and mastery of such structures.

As noted by Bulte and Housen (2014), complexity is rarely investigated for its

177 own sake but instead with the aim of diagnosing learning success. Therefore, it is

178 important to examine the effects of high/low frequency (both type and token) with the

179 attempt to understand what fosters learning of complex structures under incidental

180 exposure.

From previous research, it is known that constructions appearing in the input with

182 high frequency are acquired faster than with low frequency (Bybee, 2006; Ellis, 2001,

183 2009; Ellis \& Collins, 2009; Ellis \& Ferreira-Junior, 2009). Experimental research on the

184 role of token frequency in the incidental learning of L2 grammar demonstrated that it

185 does promote learning to some extent (Robinson, 1996, 2005). For instance, Robinson

186 (2005) found that although novice learners (L1 Japanese speakers) failed to generalize

187 the newly acquired pattern to novel items, they exhibited memorization-based learning

188 of ergativity marking in a previously unfamiliar L2 (Samoan). The study by Presson, 
189 MacWhinney, and Tokowicz (2014) is directly relevant to the present research. The

190 authors compared the effectiveness of learning under a condition in which metalinguistic

191 explanations of the rule were provided to another condition where no such information

192 was provided, both conditions being enhanced by token frequency. The authors

193 employed intentional rather than incidental learning conditions triggered by frequency

194 but found that training with the provided metalinguistic information was more beneficial

195 for learning French gender morphology among L1 English speakers. The present study

196 extends a step further, as in the current study we manipulate both type and token

197 frequencies under incidental learning conditions in order to examine their effects on the

198 acquisition of a complex morphological agreement pattern and to compare the learning

199 effect in such conditions to the explicit learning condition.

\subsection{Working memory}

202 The relationship between structure complexity and the training conditions may be

204 mediated by a third factor - the learner's WM capacity. From extensive research, we

205 know that WM - understood as a system of temporary storage and manipulation of

206 information during complex cognitive activities such as language comprehension and 
207 learning (Baddeley, 2010) - is a predictor of L2 learning success (Hummel, 2009; Juffs

208 \& Harrington, 2011; Linck, Osthus, Koeth, \& Bunting, 2014; Mackey, Philp, Egi, Fujii, \&

209 Tatsumi, 2002; Martin \& N. Ellis, 2012; Williams, 2012; Speciale, Ellis, \& Bywater,

210 2004). However, despite the overarching effect of IDs in cognitive abilities found in L2

211 morpho-syntactic acquisition (Michael \& Gollan, 2005; Miyake \& Friedman, 1998;

212 Sagarra, 2007), including grammatical agreement (Keating, 2009; Kempe, Brooks, \&

213 Kharkhurin, 2010; Sagarra, 2007; Sagarra \& Herschensohn, 2010, 2012), the traditional

214 view holds that WM is not implicated in implicit learning (Conway, Baurnschmidt,

215 Huang, \& Pisoni, 2010; Kaufman et al., 2010) or in the incidental acquisition of

216 knowledge (Brooks and Kempe, 2013; Grey, Williams, \& Rebuschat, 2015; Tagarelli et

217 al., 2011).

Accepted in the field, this perspective is nonetheless contradicted by several

219 studies that demonstrate a relationship with WM (Author, XXX; Janacsek \& Nemeth,

220 2013; Bo et al., 2011; Robinson, 2005; Weitz et al., 2011; Williams \& Lovatt, 2003).

221 Such mixed findings might be attributed to the interaction between the nature of the

222 target stimulus being acquired and the learning context, different tasks being used for 
measuring WM and implicit learning, and the L2 learning domain (e.g. comprehension

224 vs. production) being tested.

With regard to the nature of the stimulus, we know that complex items are more

226 difficult to process than simple items (Hunter, Ames, \& Koopman, 1983), while it is also

227 known that inflectional morphology has repeatedly been found to be difficult for adult L2

228 learners (Jiang, 2004, 2007). While the acquisition of complex structures depends on

229 individual differences in WM, the manner in which such a dependency interacts with

230 other factors in the learning context cannot be ignored. For instance, research suggests

231 that high token frequency mediates the availability of items in memory, leading to less

232 effort for processing (Ellis, 1996, 2001; Just \& Carpenter, 1992; Melton, 1963). Understanding how the learner's WM capacity mediates the acquisition of a

234 complex morphological pattern under different incidental learning conditions in which

235 frequency is manipulated would provide insights into whether incidental exposure, at

236 large, leads to a more successful acquisition of complex grammatical structures. The

237 present paper thus aims to further examine the combined effects of WM and frequency

238 on the successful acquisition of a complex pattern under incidental exposure. 
The present study focuses on the acquisition of a complex noun-adjective

243 agreement pattern in Russian singular and plural noun phrases by novice adult learners

244 under the three incidental learning conditions, where type and token frequencies are

245 manipulated and there is an explicit learning condition. Following Ellis (2011), we

246 adopted the following definitions of type and token frequencies: 1) token frequency

247 refers to how often a particular form with a specific lexical item appears in the input, and

248 2) type frequency accounts for the number of distinct lexical items that can be

249 substituted in a given construction.

250 In English, number is the major agreement category and bears an explicit

251 morphological marker $-s$ added to the noun's root (Eberhard, Cutting \& Bock, 2005),

252 whereas in more fusional languages, such as Russian, both the adjective and the noun

253 are inflectionally marked not only for number but also for gender and case (Lorimor et

254 al., 2008). This study uses a natural language with a complex morphology as a stimulus

255 input. It also includes measures of both receptive and productive knowledge attainment.

256 Finally, understanding the extent to which WM is engaged in incidental learning of such 
257 a structure is particularly important because, for the $\mathrm{L} 2$ learner with a relatively poor $\mathrm{L} 1$

258 morphology, acquiring fusional morphological pattern is a challenging task (Kempe and

259 MacWhinney, 1998; McDonald, 1987) that will potentially draw on available cognitive

260 resources.

261

We address several research questions. (1) How do type and token frequencies

262 affect the acquisition of receptive and productive knowledge of a complex agreement

263 pattern under incidental learning conditions? (2) Do incidental learning conditions with a

264 manipulated frequency effect lead to more effective acquisition of a complex agreement

265 structure than an explicit learning condition? (3) Is a mediating effect of WM on

266 receptive and productive knowledge acquisition observable under different learning

267 conditions?

269 4. Method

A between-subjects design was employed such that the learners were assigned

272 to one of the incidental learning conditions or the explicit learning condition. In L2

273 research, implicit/incidental learning research training conditions are often manipulated 
on a continuum from explicit learning conditions, in which learners are provided with

275 metalinguistic information (e.g., pedagogical rules) (DeKeyser, 1995; Norris \& Ortega,

276 2000; Robinson, 1996), to implicit learning conditions, in which participants are asked to

277 focus on meaning and are not informed about the testing that will follow (Rebuschat \&

278 Williams, 2012; Tagarelli et al., 2011). Following the implications of the findings by

279 Presson et al. (2014) and the vision that the rule-search condition allows for a certain

280 degree of implicitness during learning, we employed metalinguistic explanations of the

281 rule as a method of training in the explicit learning condition. The amount of time spent

by participants during training in the explicit and the incidental learning conditions was

284 production tasks.

\subsection{Participants}

study (males: $n=21$; females: $n=59$ ). Following Leung and Williams (2011), 
292 from the study. The participants were students of humanities $(n=48)$, social sciences $(n$

$293=12)$, or natural sciences $(n=15)$ or were members of the administrative staff $(n=5)$ at

294 a large university and were randomly allocated to one of the four learning conditions ( $n$

$295=20$ per condition). Participants received either course credit or monetary

296 compensation for their participation.

304 the pictures (e.g., small, white, old) were selected. All nouns were concrete nouns maintain a consistent pattern, only nouns and adjectives that belonged to the inflectional 
310 with -ek in the genitive case plural, such as babushka 'grandmother' (pl. babushek),

311 were excluded.

316 nominative, dative, instrumental, and genitive cases for singular and plural forms of the

317 noun, and each adjective was paired with only one noun to create a novel phrase. The

318 four cases were selected based on how easy it would be to create a short story. Each

319 story depicted feminine or masculine characters and consisted of eight slides presented

320 sequentially, (four that corresponded to the agreement in the singular (nominative,

321 dative, instrumental and genitive) and four that correspond to agreement in the plural

322 (nominative, dative, instrumental and genitive)) presented sequentially. Each slide

323 contained a picture and a Russian sentence, as illustrated in Figure 1 and Table 2.

324 There were 7 novel stories in the high type frequency condition and 3 - in the low type

325 frequency condition. A token represented the repetition of a particular story and

326 therefore of the specific noun-adjective phrase in a certain agreement form (e.g.,

327 malomu karliku 'towards the short dwarf; masculine, dative, singular). Thus, there were 
3287 repetitions of each story in the high token frequency condition and 3 in the low token

329 frequency condition (see Table 3 for the breakdown of trials in each condition).

330 Therefore, on the basis of this there were the following conditions created and

331 participants were allocated to the following groups: high type/low token frequency, low

332 type/high token frequency and low type/low token frequency.

\subsection{WM testing} An operation span task (Unsworth, Heitz, Schrock, \& Engle, 2005) was used to

341 measure WM. This task was obtained from the Attention and WM Lab at Georgia

342 Institute of Technology and has been previously used in several studies (Redick et al.,

343 2012; Turner \& Engle, 1989; Unsworth \& Engle, 2008). The operation span task (Juffs \& 
344 Harrington, 2011) is a complex WM span task that measures both the storage and

345 processing components of WM.

In this task, participants were presented with simple arithmetical operations, such

347 as $(2 \times 1)+1=3$, and were asked to judge their correctness as quickly as possible by

348 mouse-clicking a true or false box on the computer screen. Immediately after each

349 operation was judged, an English letter appeared on the screen, and participants were

350 instructed to memorize the letters in the order in which they were presented. Following

351 Unsworth et al. (2005), the OSpan score was calculated as the sum of all set sizes that

352 were perfectly recalled, considering the order of presentation. The highest possible

353 score was 75.

354

\subsection{Procedure}

358 the training and the testing phases. The testing phase consisted of two immediate post-

359 tests that measured receptive and productive knowledge. 

For the vocabulary test, participants were instructed to memorize the six target

363 Russian nouns, four adjectives, three prepositions, and the particle eto (see Appendix)

364 while reading through the slides on their computer screens at their own pace. Each slide 365 contained a Russian word (transliterated into the Latin alphabet), its English translation, 366 and a matching picture. The adjectives were presented in the masculine gender,

367 nominative case, and singular form. Following the memorization phase, participants

368 completed the vocabulary test. They saw a picture and a transliterated Russian word

369 presented via E-Prime 2 (Psychology Software Tools, Pittsburgh, PA) and were asked

370 to press 1 (match) or 2 (mismatch) on the keyboard to indicate whether the word

371 matched the picture. After their response, either Correct or Incorrect, together with the

372 overall percentage score, appeared on the computer screen. Participants had to score

373 at least $85 \%$ on the vocabulary test to proceed to the training phase.

377 linguistic structure or that there would be a testing phase. These participants were 
randomly assigned to one of the three incidental learning conditions (low type/high

379 token, low type/low token, high type/low token frequency). Depending on the condition,

380 they were presented with varying numbers of types and tokens for the training items

381 (see Table 3). Participants were informed that they were going to view stories about

382 different characters and that their task was to look at the pictures, read the Russian

383 sentences silently and try to understand the meaning. Participants received the

384 following instructions: "Now you will see stories about different characters. Please, look

385 at the picture, read the sentence to yourself and try to understand its meaning". In each

386 condition, as presented on the computer screen via E-Prime 2 (Psychology Software

387 Tools, Pittsburgh, PA), participants viewed sequences of pictures about stereotypical

388 story characters of masculine and feminine grammatical gender overlapping with their

389 biological gender and written Russian sentences containing the agreement pattern in

390 singular and plural forms. Each sequence contained eight pictures that were presented

391 for $3000 \mathrm{~ms}$ each in the following order: nominative (singular, plural); dative (singular,

392 plural); instrumental (singular, plural); and genitive cases (singular, plural) (see Figure

393 1). Each slide contained a Russian sentence with embedded noun-adjective agreement

394 in singular or plural form and a picture representing a boy going towards, with or away 
395 from a stereotypical story character or characters of a feminine or a masculine gender

396 (e.g., dwarf). The presentation of each sequence was randomized.

401 metalinguistic information about noun-adjective agreement and were informed that they

402 would be tested on their acquisition of this knowledge. Agreement according to number,

403 gender and case was explained using two examples for each agreement rule. Each

404 example was represented by a slide containing a Russian sentence that was

405 transliterated into the Latin alphabet with adjectival and noun endings highlighted in

406 bold, an English translation written underneath the transliteration and a semantically

407 corresponding picture similar to the pictures presented to participants in the incidental

408 learning conditions. After receiving metalinguistic explanations regarding the agreement

409 rules, participants were given 15 minutes to examine the slides again at their own pace

410 and to memorize the morphological pattern. 
414 task immediately after training. The recognition task was a number decision task that

415 tested their receptive knowledge of the agreement pattern in all its possible variations.

416 Such a task draws more upon implicit processing than a grammaticality judgement task

417 (GJT) (Anton-Mendez, 1999). The researchers assessed whether the learner could

418 abstract the notion of plurality/singularity expressed by the complex pattern of

419 inflectional markers different across the masculine and feminine agreement

420 constructions in different cases that were presented during training. Participants were

421 told that they would next see sentences similar to those they had previously seen, and

422 they were asked to press 1 to indicate that the sentence described one character or 2 if

423 the sentence described more than one character. The test consisted of 28 grammatical

424 Russian sentences. There were 14 old items, i.e., sentences presented during training,

425 and 14 new items, i.e., sentences composed of previously unseen nouns and

426 adjectives. If no response was recorded, each stimulus would time out after $3000 \mathrm{~ms}$.

427 Sentences presented during training and containing familiar adjectival phrases were

428 included to test whether the learning was based on memorization, whereas new items 

were included to test whether participants could generalize acquired knowledge to new

430 instances. The same factors that were controlled in the training items were controlled in

431 the new items. Accuracy of the participant response and reaction time $(R T)$ on each

432 item were collected during the recognition task via E-Prime 2. After completing the recognition task, participants were asked to complete a fill-

434 in-the-blank production task that consisted of 28 slides containing pictures and

435 grammatical Russian sentences (14 old and 14 new). In each block, half of the stimuli

436 consisted of agreement in the singular and half consisted of agreement in the plural.

437 Across the blocks, there were seven items with agreement in the feminine singular,

438 seven in the feminine plural, seven in the masculine singular, and seven in the

439 masculine plural. Participants had to fill in a blank for the adjectival ending (e.g., Idu $k$

440 mal_ karliku 'I am going towards the small dwarf'); accuracy for each item were

441 recorded. Production and recognition tasks were counterbalanced across the

442 participants, with half of the participants completing a recognition task first, and half $-\mathrm{a}$

443 production task first. All tasks were completed in one session, which lasted between 60

444 and 90 minutes. 


\section{Results}

The data were analysed using logistic and linear regression models in $R$,

448 version 3.2.3, by applying a Generalized Linear Model (GLM) in the R Commander

449 software package (R Development Core Team, 2015). We checked for normality and

450 homogeneity by visual inspections of the plots of residuals against fitted values. A

451 backwards model selection procedure was employed that began with a full model

452 including all parameters and then excluded the parameters one at a time. An ANOVA

453 function was used to determine whether the parameter significantly improved the model

454 (Baayen, 2008). When fitting the model, all fixed effects of theoretical interest were

455 retained in the models, even if they were non-significant. For a summary of model

456 coefficients, see Table 4. Throughout the paper, MCMC-estimated $p$ values that are

457 considered significant at the $\alpha=0.05$ level are presented.

5.1. Explicit vs incidental learning

460

461 The responses were scored for accuracy. A response was coded as correct if the

462 learner was able to recognize the number agreement or produce the complete 
appropriate ending for the agreement pattern. Each participant received a maximum of

46428 points for correct responses in calculating their accuracy scores (see Table 5 for the 465 overall accuracy and WM scores). Although general performance for comprehension 466 accuracy was above chance (see Figure 2 for mean scores per condition), production 467 levels under all conditions were low (Figure 3).

475 token; low type/low token frequency), block (old items, new items; with old items used

476 as a reference category) and the operation span score were included in the model as

477 fixed effects, and item was entered as a random effect. The data were treatment-coded

478 for learning condition. To compare the effectiveness of the learning condition on

479 knowledge retention, the explicit learning condition was used as the reference category. 
481 learning) condition exhibited higher accuracy for comprehension of the agreement

482 pattern than participants in the explicit learning condition. Individual reaction times (RTs)

483 collected during the recognition task exceeding $\pm 2 S D$ were eliminated. The mean error

484 rate was $0.2 \%$. We then ran a linear regression with $g / m e r$ model function with

485 condition (explicit learning, high type/low token; low type/high token; low type/low token

486 frequency), block (old items, new items) and operation span score as fixed effects and

487 with item as the random effect to investigate the differences in $R T \mathrm{~s}$. Significantly shorter

$488 R T s$ were found for the participants in the low type/low token frequency condition than

489 for those in the explicit learning condition; moreover, participants in the latter group also

490 performed less accurately in agreement comprehension. However, with respect to

491 comprehension accuracy and RTs, no difference between old and new items was

492 found, and there was no effect of WM on either comprehension accuracy or RTs.

493

494

FIGURE 4

495

TABLE 6

496 
498 that 1 indicated that the participant produced a complete adjectival ending in a relevant

499 position and 0 indicated that the participant produced either no ending or an inaccurate

500 ending. The same model used in the analysis of comprehension accuracy was run to

501 determine production accuracy. The analysis revealed that participants in the explicit

502 learning condition significantly outperformed participants engaged in all of the incidental

503 learning conditions in the production of complete endings. Moreover, it was determined

504 that participants correctly answered questions regarding old items significantly more

505 than new items. Finally, in contrast to production, there was an effect of WM on

506 productive knowledge retrieval.

\section{TABLE 7}

5.2. Frequency and knowledge acquisition under incidental learning conditions

512 To further explore the effect of frequency on incidental learning, we ran the same model

513 but included only the incidental conditions. The model included condition (high type/low

514 token; low type/high token; low type/low token frequency), block (old items, new items; 
515 with old items as a reference category) and operation span scores as fixed effects and

516 item as a random effect.

5.2.1. Frequency and receptive knowledge

520 The analysis using the model with the high type/low token frequency condition as a

521 reference category revealed that participants in the low type/high token condition $(M=$

$52284.50 \%, S D=11.50 \%, \beta=-3.83$, Wald $z=-2.05, S E=1.87, p=.04)$ and the low

523 type/low token frequency $(M=70.50 \%, S D=27.80 \%)$ condition recognized the

524 agreement pattern less accurately than participants in the high type/low token frequency

525 Condition $(M=89.50 \%, S D=5.90 \% ; \beta=-1.17$, Wald $z=-6.74, S E=1.74, p<.001)$.

526 We then ran the same model using the low type/low token frequency condition as a

527 reference category and found that participants in the low type/high token frequency

528 condition performed significantly better than participants in the low type/low token

529 frequency condition $(\beta=7.88$, Wald $z=5.21, S E=1.51, p<.001)$. No significant

530 difference between old vs new items with respect to participant accuracy was found $(\beta=$

5317.28$, Wald $z=1.32, S E=5.53, p=.18)$. 
533 those used for the analysis of comprehension accuracy. There was no significant

534 difference between participants' response times for those in the high type/low token

535 condition $(M=1014.58, S D=20.76)$ and those in the low type/high token frequency

536 condition $(M=1034.64, S D=23.20, \beta=6.97, t$ value $=.20, S E=37.02, p=.84)$.

537 However, the response times for those in the low type/low token frequency condition

538 were significantly shorter than the response times for those in the high type/low token

539 condition $(\beta=-132.52, t$ value $=-3.76, S E=35.26, p<.001)$. When running the model

540 for the low type/low token frequency condition $(M=896.50, S D=27.50)$ as the

541 reference category, it was found that participants' $R T$ s in the low type/high token

542 frequency condition $(\beta=139.50, t$ value $=4.12, S E=33.90, p<.001)$ were also

543 significantly longer than the RTs for participants in the low type/low token frequency

544 condition. No significant difference was found in participants' accuracy between old and

545 new items $(\beta=-49.65, t$ value $=-.48, S E=103.54, p=.63)$, and no WM effect was

546 found for either comprehension accuracy $(\beta=8.58$, Wald $z=1.58, S E=5.43, p=.11)$

547 or $R T s(\beta=1.60, t$ value $=1.49, S E=1.07, p=.14)$. 
accuracy was employed for investigating production accuracy. First, the model was run

with high type/low token frequency as a reference level and determined that participants

554 in the low type/high token frequency condition were more likely to recall the correct

555 adjectival ending $(M=13.90 \%, S D=14.9 \%)$ than participants in the high type/low token

556 frequency condition $(M=8.60 \%, S D=9.90 \%, \beta=5.46$, Wald $z=2.62, S E=2.08, p=$

557 .009). Production accuracy performance did not differ between participants in the low

558 type/low token frequency condition $(M=9.80 \%, S D=10.50 \%)$ and the high type/low

559 token frequency condition $(\beta=1.14$, Wald $z=.52, S E=2.22, p=.61)$. The analysis of

560 the low type/low token frequency condition as a reference category indicated that

561 participants in the low type/high token frequency condition recalled endings more

562 accurately than those in the low type/low token frequency condition $(\beta=4.39$, Wald $z=$

$5632.25, S E=1.95, p=.02)$. Participants also recalled significantly more correct endings

564 for old items than for new items $(\beta=1.95$, Wald $z=2.94, S E=6.63, p=.03)$. Finally,

565 with respect to comprehension, the analysis revealed that WM had no significant effect

566 on production $(\beta=7.85$, Wald $z=1.20, S E=6.57, p=.23)$. 
568 6. Discussion

569

570 This study aimed to investigate the roles of type and token frequencies in the

571 incidental acquisition of a complex noun-adjective agreement pattern and the mediating

572 effect of individual differences in learners' WM. We were interested in examining the

573 extent to which the combined effects of frequency in the incidental input and the

574 learner's WM might help to override the lack of explicit instruction when acquiring a

575 complex structure.

576 Our findings indicate that even during the initial stages of learning under

577 incidental exposure, speakers of an L1 with a relatively poor morphological system were

578 sensitive to morphological cues and could successfully recognize plurality represented

579 by a complex morphological pattern. This confirms previous research on languages with

580 less fusional morphology, such as in L2 Spanish and French (De Garavito \& White,

581 2002; McCarthy, 2008; White et al., 2004), and on languages with a high fusional

582 agreement morphology, such as Russian (Brooks, Kempe, \& Sionov, 2006; Kempe et

583 al., 2010), as well as incidental learning studies regarding the acquisition of complex 
584 morphological systems (Brooks \& Kempe, 2013; Rogers, Revesz, \& Rebuschat, 2015).

585 The accessibility of the concept of plurality, based on the dichotomous distinction

586 between one and more than one referent (Dispaldro, Ruggiero, \& Scali, 2014) may

587 provide an additional contribution to the learning of such complex morphological

588 patterns. Although grammaticalized in English, number is believed to be prelinguistic in

589 nature and more semantically salient (Dispaldro, Ruggiero, \& Scali, 2014; Eberhard,

590 1999).

Moreover, the complexity of the stimulus itself may facilitate its proneness to

being better captured by the implicit learning mechanisms. Even within the artificial

593 language learning paradigm, research demonstrates a stronger learning effect when the

594 input was complex and contained multiple levels of regularities as opposed to when it

595 was simplified (Saffran \& Wilson, 2003; Thiessen \& Saffran, 2009). Since natural

596 languages are believed to be inherently richer in cues and complexity than artificial

597 language systems (Erickson \& Thiessen, 2015), when employing a natural language as

598 a stimulus in research, more pronounced incidental learning effect may be found.

599 In addition, despite the assumption that utilizing artificial language systems in

600 incidental learning experiments, generally provides insight into the natural language 
importance of employing more natural language stimuli in current incidental learning

610 metalinguistic information. This finding is consistent with the theoretic stipulation that

611 incidental exposure bestows a greater advantage on learning a complex grammatical

612 structure (Krashen, 1982, 1994; Reber, 1989), and it also confirms the existent research

613 that provides evidence of higher knowledge attainment under incidental learning

614 conditions as opposed to intentional learning conditions (DeKeyser, 1995; Robinson,

615 1996) in adult L2 learners. It is widely acknowledged in the literature that L2 inflectional

616 morphology represents the greatest challenge for learners compared to other areas of

617 morpho-syntax (DeKeyser, 2005; Larsen-Freeman, 2010). This premise is confirmed by 
619 in word order acquisition compared to morphology (Grey et al., 2014). Moreover, during

620 the post-critical period age, such knowledge must be acquired explicitly and be

621 triggered by declarative mechanisms, as some theories suggest (Ullman, 2004).

622 Therefore, the high learning effect obtained in the present study under the incidental

623 learning condition and enhanced by type frequency supports both the assumption that

624 incidental exposure can help adults to override maturational constraints on learning and

625 Krashen's claim (Krashen, 1982, 1994), with the correction, however, that an incidental

626 learning mode requires additional triggers. The role of frequency, as one such trigger, is

627 generally consistent with the cognitive-associative view of L2 acquisition (N. Ellis, 2002;

628 2012) and the research that demonstrates the positive frequency impact on L2

629 morphology learning (Bowden, Gelfand, Sanz, \& Ullman, 2010).

630 Overall, as our findings suggest, although the participants in the explicit learning

631 conditions exhibited higher production accuracy than those in the incidental learning

632 conditions, the explicit learning mode was not effective for acquiring a complex pattern.

633 In the present study, performance, even in production domain, that is dependent on

634 higher order processes (Keenen \& MacWhinney, 1987) and conscious knowledge 
635 remained below chance in all learning conditions, including the explicit learning

636 condition. Future research may consider ways to improve such performance in a

637 longitudinal study. Perhaps adopting a paradigm in which training is conducted over

638 multiple sessions would help to identify those factors involved in successful productive

639 knowledge acquisition and the exposure mode that is most beneficial.

640

641

642

644 learning condition and provides interesting and differential effects for the productive and

645 receptive acquisition of a complex pattern under incidental exposure. Receptive

646 knowledge acquisition is affected by type frequency, whereas productive knowledge

647 acquisition is affected by token frequency. According to Bybee (1985), type frequency

648 promotes the generalization of grammatical structures. Thus, for successful recognition,

649 the learner must develop an abstract schema by collecting a sizeable number of types

650 of a given construction (Bybee \& Thompson, 2000; N. Ellis, 2002; Plunkett \&

651 Marchman, 1991). Our findings indicate that the larger the number of different lexical 
652 items appearing within a complex stimulus pattern during training, the more accurate

653 the identification and generalization of the agreement structure.

654 For productive knowledge acquisition, frequency interacts differently with the

655 incidental learning condition and the complex stimulus input, providing a higher learning

656 effect under the condition with high token frequency. This indicates that the item-based

657 learning trend is similar to L1 acquisition, where a learner begins with memorizing the

658 pattern based on specific construction examples (Braine and Brooks, 1995; Brooks,

659 Tomasello, Dodson and Lewis, 1999; Tomasello, 2000, 2008). The item-based learning

660 effect is also supported by the finding that participants performed better on old items

661 than on new items with respect to production but not with respect to comprehension.

662 Such a discrepancy in frequency effects for learning incidentally between

663 production and comprehension reinforces the general assumption that comprehension

664 precedes production in language acquisition (e.g., learning of morphology in children)

665 (Clark \& Hecht, 1982); the acquisition of singular-plural constructions (Fraser, Bellugi, \&

666 Brown, 1963), and the L2 adult learning of inflectional morphology (Fenson, Dale,

667 Reznick, Bates, et al., 1994). It also reflects the differences in the sub-processes

668 involved in production and comprehension (Tanner, Nicol \& Brehm, 2014). 
670 structure under incidental exposure in different modalities and the extent to which we

671 can examine effective learning in the production domain, a more extended study may

672 be insightful. For instance, providing enhanced training over several sessions or

673 manipulating different degrees of frequency in the input would yield a more

674 comprehensive picture.

675

676 6.2. Working Memory

677 Finally, we also aimed to explore the mediating effect of WM on the acquisition of

678 a complex structure under different incidental learning conditions enhanced by type and

679 token frequencies. The null WM effect indicates that it is the frequency alone that

680 shapes the learning of a linguistically complex structure. One possible explanation,

681 which is also consistent with the assumption of automaticity and the effortless nature of

682 the implicit learning process (Shiffrin and Schneider, 1977), is that when the stimulus is

683 sufficiently complex, implicit learning mechanisms underpin such learning without

684 relying on cognitive resources. 
686 ample evidence suggesting that WM is not implicated. This applies to those studies

687 focusing on the relationship between WM and grammatical knowledge acquisition under

688 incidental learning conditions (Tagarelli et al., 2011, 2016; Yang \& Li, 2012), to studies

689 employing sequence learning (Conway et al., 2011; Kaufman et al., 2010), and to

690 research focusing on the productive acquisition of a Russian case-marking system

691 (Brooks and Kempe, 2013).

692

An alternative interpretation of the null WM effect could relate to the nature of the agreement structure used in the present study. It might be the case that plurality itself

694 may induce a processing cost (Tanner et al., 2014) or that the linguistic complexity of

695 the morphological system, which factors in several agreement variables, places a high

696 cognitive demand on knowledge retrieval, thus hindering access to WM (Caplan and

697 Waters, 1999; Hopp, 2006, 2010; McDonald, 2006). This line of thinking may suggest

698 that the structure employed in the current study was, in principle, too complex to be

699 acquired, regardless of individual variations among learners with respect to their WM

700 capacity. For instance, Sagarra (2007), who investigated agreement processing in L2,

701 found that WM was engaged when the complexity of the target structure was low but 
702 that WM was not involved in the processing of more complex structures. WM was found

703 to be a predictor for understanding sentences with within-phrase gender agreement

704 violations (e.g., La mujer lava la blusa *blanco en la cocina 'The woman washes the

705 *white (masc) blouse (fem) in the kitchen') by English L2 learners of Spanish but was

706 not a predictor for sentences that contained gender agreement violations across

707 clauses, which represents a more challenging task for the learner. In this sense, the

708 linguistic complexity of the structure under investigation taps into cognitive complexity.

709 The null correlation with WM may indicate that the present pattern is more cognitively

710 demanding for all language learners (Housen \& Simoens, 2016) when it is to be

711 acquired without intention and awareness.

712 In spite of the positive results reported herein, one possible limitation of the

713 present study involves the comparability between explicit and incidental learning

714 conditions. The rationale behind choosing the metalinguistic explanation training rather

715 than employing a rule-search condition involves the robust learning effect typically

716 reported in the literature in the explicit learning conditions where metalinguistic

717 information about the target structure was provided to the learner. Another potential

718 limitation of the study was the difficulty in teasing apart the categories of gender, case 
719 and number when testing the acquisition of a complex agreement pattern. A similar

720 challenge was recorded by Brooks, Kempe and Sionov (2006) and attributed to the

721 inflectional syncretism of the Russian language. However, obtaining information about

722 how well each of the grammatical category was learned by future research might

723 provide a better understanding about acquisition of complex systems. Finally, exploring

724 how other factors, such as stereotypical gender (Molinaro, Su \& Carreiras, 2016;

725 Siyanova-Chanturia, Pesciarelli \& Cacciari, 2012) of the stimuli used in the present

726 study, may foster learning of a morphological pattern could be another potential trend of

727 research. Despite its limitations, nevertheless, the advantage of the current research is

728 its contribution to the growing understanding of L2 grammatical acquisition and its use

729 of a natural language system. Studies of the incidental learning of natural language

730 grammars are limited because research traditionally used artificial languages. Despite

731 providing control over confounding factors, artificial languages present a much-

732 simplified version of natural language (Hulstijn et al., 2014). 
736 complex synergies of the complexity of the target structure being acquired and the

737 learning context with available facilitating factors. This study offers evidence that the

738 incidental learning condition can be more beneficial for receptive acquisition of a

739 complex structure if fostered by type frequency. It shows that within the receptive

740 domain a complex grammatical structure can be acquired incidentally more effectively,

741 even when compared to the explicit learning mode. This evidence is in line with the

742 theoretical claim that a complex grammatical structure is best to be learned

743 incidentally/implicitly (Krashen, 1982, 1994; Reber, 1989). Moreover, our study also

744 provide empirical evidence for the suggestion that in order to better understand the

745 acquisition of complex structures incidentally it is necessary to study the interaction

746 between the learning condition and the role of other facilitating factors - such as

747 frequency - in the input (Hulstijn, 2005). However, further research is needed to

748 illuminate productive acquisition. Generally, our findings add to the existing incidental

749 learning research and to the usage-based approach to second language acquisition ( $\mathrm{N}$.

750 Ellis, 2002, 2012). 
754 Andringa, S., De Glopper, K., \& Hacquebord, H. (2011). Effects of explicit and implicit

755 instruction on free written response task performance. Language Learning, 61, 868 756903.

757 Arnon, I., \& Snider, N. (2010). More than words: Frequency effects for multi-word

758 phrases. Journal of Memory \& Language, 62, 67-82.

759 Baddeley, A. (2010). Working memory. Current Biology, 20 (4), 136-140.

760 Barber, H., \& Carreiras, (2005). Grammatical gender and number agreement in

761 Spanish: An ERP comparison. Journal of Cognitive Neuroscience, 17, 137-153.

762 Baayen, R. (2008). Analyzing Linguistic Data. A Practical Introduction to Statistics Using

763 R. Cambridge University Press.

764 Blackwell, A., \& Bates, E. (1995). Inducing agrammatic profiles in normals: Evidence for 765 the selective vulnerability of morphology under cognitive resource limitation. Journal 766 of Cognitive Neuroscience, 7, 228-257. 
Bo, J., Jennett, S., \& Seidler, R. (2011). Working memory capacity correlates with implicit serial reaction time task performance. Experimental Brain Research, 214 (1), 73-81.

770 Bock, K. (1987). An effect of the accessibility of word forms on sentence structures. Journal of Memory \& Language, 26, 119-137.

Bock, K, \& Irwin, D. (1980). Syntactic effects of information availability in sentence production. Journal of Verbal Learning \& Verbal Behavior, 19, 467-484.

774 Bock, K., \& Warren, R. (1985). Conceptual accessibility and syntactic structure in 775 sentence formulation. Cognition, 21, 47-67.

776 Bowden, H., Gelfand, M., Sanz, C., \& Ullman, M. (2010). Verbal inflectional morphology composition. Language Learning, $60(1), 44-87$.

779 Braine, M., \& Brooks, P. (1995). Verb argument structure and the problem of avoiding an overgeneral grammar. In Tomasello, M., \& Merriman, W (eds.) Beyond Names for Things: Young Children's Acquisition of Verbs. Hillsdale, NJ: Erlbaum, 352-376.

782 Brooks, P, \& Kempe, V. (2013). Individual differences in adult foreign language learning:

783 The mediating effect of metalinguistic awareness. Memory \& Cognition 41, 281-296. 
784 Brooks, P., Tomasello, M., Dodson, K, \& Lewis, L. (1999). Young children's overgeneralizations with fixed transitivity verbs. Child Development, 70, 1325-1337.

Bulté, B., \& Housen, A. (2012). Defi ning and operationalising L2 complexity. In A. ciency —investigating complexity, accuracy and fl uency in SLA (pp. 21 - 46). Amsterdam/Philadelphia: John Benjamins.

Bulté, B., \& Housen, A. (2014). Conceptualizing and measuring short-term changes in L2 writing complexity. Journal of Second Language Writing, 26, 42-65.

Bybee, J. (1985). Morphology: A Study of the Relation Between Meaning and Form. Philadelphia, PA: John Benjamins.

794 Bybee, J, \& Thompson, S. (2000). Three frequency effects in syntax. Berkeley Linguistic Society, 23, 378-388.

Caplan, D., \& Waters, G. (1999). Verbal working memory and sentence comprehension. Behavioral Brain Science, 22, 77-94.

798 Christiansen, M., \& Chater, N. (1999). Towards a connectionist model of recursion in human linguistic performance. Cognitive Science, 23, 157-205. 
800 Clark, E., \& Hecht, B. (1983). Comprehension, production, and language

801 acquisition. Annual Review of Psychology, 34, 325-349.

802 Collins, L. (2004). The particulars on universals: A comparison of the acquisition of 803 tense-aspect morphology among Japanese and French-speaking learners of

804 English. Canadian Modern Language Review, 61, 251-274.

805 Collings, L., Trofimovich, P., White, J., Cardoso, W., \& Horst, M. (2009). Some input on 806 the easy/difficult grammar question: An empirical study. The Modern Language 807 Journal, 93, 336-353.

808 Conway, C., Baurnschmidt, A., Huang, S., \& Pisoni, D. (2011). Implicit statistical 809 learning in language processing: Word predictability is the key. Cognition, 114, 356$810 \quad 371$.

811 Dahl, Ö. (2004). The Growth and Maintenance of Linguistic Complexity. John 812 Benjamins Publishing.

813 de Graaff, R. (1997). The eXperanto experiment: Effects of explicit instruction on 814 second language acquisition. Studies in Second Language Acquisition, 19, 249-297.

815 DeKeyser, R. (1995). Learning second language grammar rules: An experiment with a 816 miniature linguistic system. Studies in Second Language Acquisition, 17, 379-410. 
817 DeKeyser, R. (2000). The robustness of critical period effects in second language

818 acquisition. Studies in Second Language Acquisition, 22, 499-533.

819 DeKeyser, R. (2005). What makes learning second-language grammar difficult? A

820 review of issues. Language Learning, 55, 1-25.

821 DeKeyser, R., \& Sokalski, K. (1996). The differential role of comprehension and production practice. Language Learning, 46, 613-642.

823 De Vincenzi, M., \& Di Domenico, E. (1999). A distinction among features: the role of 824 gener and number in the retrieval of pronoun antecendents. Rivista di linguística, 11, $825 \quad 41-74$.

826 Dornyei, Z. (2005). The Psychology of the Language Learner. Hillsdale, NJ: Erlbaum Associates.

828 Eberhard, K. (1999). The accessibility of conceptual number to the processes of subject-verb agreement in English. Journal of Memory and Language, 41, 560-578.

830 Eberhard, K, Cutting, J, \& Bock, K. (2005). Making syntax of sense: number agreement 831 in sentence production. Psychological Review, 112, 531.

832 Ellis, N. (1993). Rules and instances in foreign language learning: interactions of implicit and explicit knowledge. European Journal of Cognitive Psychology, 5, 289-318. 
834 Ellis, N. (2002). Frequency effects in language processing: A review with implications

835 for theories of implicit and explicit language acquisition. Studies in Second Language

836 Acquisition, 24, 143-188.

837 Ellis, N. (2005). At the interface: dynamic interactions of explicit and implicit language

838 knowledge, Studies in Second Language Acquisition, 27, 305-352.

839 Ellis, N. (2006). The associative-cognitive CREED. In VanPatten, B., \& Williams, J.

840 (eds). Theories in Second Language Acquisition: An introduction. Cambridge: CUP.

841 Ellis, N. (2012). Formulaic language and second language acquisition: Zipf and the phrasal teddy bear. Annual Review of Applied Linguistics, 32, 17-44.

843 Ellis, N., \& Ferreira-Junior, F. (2009). Construction learning as a function of frequency,

844 frequency distribution, and function. The Modern Language Journal, 93, 370-385.

845 Ellis, N., Frey, E., \& Jalkanen, I. (2008). The psycholinguistic reality of collocation and semantic prosody: Lexical access. In: Romer, U., \& Schulze, R. (eds.) Exploring the Lexis-grammar Interface. Amsterdam, the Netherlands: John Benjamins.

848 Ellis, N., O'Donnell, M., \& Romer, U. (2014). The processing of verb-argument

849 constructions is sensitive to form, function, frequency, contingency and

850 prototypicality. Cognitive Linguistics, 25, 55-98. 
851 Elman, J. (1991). Distributed representations, simple recurrent networks, and

852 grammatical structure. Machine Learning, 7, 195-225.

853 Erickson, L., \& Thiessen, E. (2015). Statistical learning of language: theory, validity, and 854 predictions of a statistical learning account of language acquisition. Developmental 855 Review, 37, 66-108.

856 Ettlinger, M., Morgan-Short, K., Faretta-Stutenberg, M., \& Wong, P. (2016). The 857 science, $40(4), 822-847$.

859 Godfroid, A. (2016). The effects of implicit instruction on implicit and explicit knowledge development. Studies in Second Language Acquisition, 38(2), 177-215.

861 Grey, S., Williams, J. N., \& Rebuschat, P. (2014). Incidental exposure and L3 learning 862 of morphosyntax. Studies in Second Language Acquisition, 36, 1-34.

863 Hopp, H. (2006). Syntactic features and reanalysis in near-native processing. Second 864 Language Research, 22, 369-397.

865 Hopp, H. (2010). Ultimate attainment in L2 inflection: Performance similarities between non-native and native speakers. Lingua, 120, 901-931. 
867 Housen, A. (2014). Difficulty and complexity of language features and second language instruction. The Encyclopedia of Applied Linguistics, 1-7.

869 Housen, A., Pierrard, M., \& Van Daele, S. (2005). Structure complexity and the efficacy of explicit grammar instruction. In Housen, A., \& Pierrard, M. (eds.) Investigations in Instructed Second Language Acquisition. Berlin and New York: Mouton de Gruyter, 235-270.

873 Housen, A., \& Simoens, H. (2016). Introduction: Cognitive perspectives on difficulty and 175.

Hulstijn, J. (2005) Theoretical and empirical issues in the study of implicit and explicit second-language learning. Studies in Second Language Acquisition, 27, 129140.

879 Hulstijn J, \& de Graaff, R. (1994). Under what conditions does explicit knowledge of a 880 second language facilitate the acquisition of implicit knowledge? A research proposal. AlLA Review, 11, 97-112.

882 Hummel, K. (2009). Aptitude, phonological memory, and second language proficiency in non-novice adult learners. Applied Psycholinguistics, 30, 225-249. 
884 Hunter, M., Ames, E., \& Koopman, R. (1983). Effects of stimulus complexity and

885 familiarization time on infant preferences for novel and familiar

886 stimuli. Developmental Psychology, 19 (3), 338-352.

887 Janacsek, K., \& Nemeth, D. (2013). Implicit sequence learning and working memory:

$888 \quad$ correlated or complicated? Cortex, 49 (8), 2001-2006.

889 Jiang, N. (2004). Morphological insensitivity in second language processing. Applied

$890 \quad$ Psycholinguistics, 25, 603-634.

891 Jiang, N. (2007). Selective integration of linguistic knowledge in adult second language

892 learning. Language Learning, 57, 1-33.

893 Jiang, N., \& Nekrasova, T. (2007). The processing of formulaic sequences by second

894 language speakers. The Modern Language Journal, 91, 433-445.

895 Juffs, A., \& Harrington, M. (2011). Aspects of working memory and L2 learning.

$896 \quad$ Language Teaching, 44, 137 - 166.

897 Johnson, J., \& Newport, E. (1989). Critical period effects in second language learning:

898 The influence of maturational state on the acquisition of English as a second

899 language. Cognitive Psychology, 21 (1), 60-99. 
Just, M., \& Carpenter, P. (1992). A capacity theory of comprehension: Individual

901 differences in working memory. Psychological Review, 99, 122-149.

902

Kaufman, S., Deyoung, C., Gray, J., Jiménez, L., Brown, J., \& Mackintosh, N. (2010).

903 Implicit learning as an ability. Cognition, 116, 321-340.

904 Kempe, V., Brooks, P., \& Kharkhurin, A. (2010). Cognitive predictors of generalization of 905 Russian grammatical gender categories. Language Learning, 60, 127-153.

906

Kempe, V., \& MacWhinney, B. (1998). The acquisition of case marking by adult learners of Russian and German. Studies in Second Language Acquisition, 20, 543-587.

908 Keenan, J. M., \& MacWhinney, B. (1987). Understanding the Relationship between

909 Comprehension and Production. In H. W. Dechert \& M Raupach (Eds.),

910 Psycholinguistic Models of Production (pp. 149-155). Norwood, N.J.: Ablex

$911 \quad$ Publishing Corporation.

912 Krashen, S. (1982). Principles and Practive in Second Language Acquisition. Oxford:

913 Pergamon.

914 Krashen, S. (1994). The input hypothesis and its rivals. In Ellis N (eds.) Implicit and

915 Explicit Learning of Languages. London: Academic Press, 45-77.

916 Kusters, W. (2003). Linguistic Complexity. Netherlands Graduate School of Linguistics. 
Larsen-Freeman, D. (2010). Not so fast: A discussion of L2 morpheme processing and acquisition. Language Learning, 60, 221-230.

919 Linck, J., Osthus, P., Koeth, J., \& Bunting, M. (2014). Working memory and second 920 language comprehension and production: A meta-analysis. Psychonomic Bulletin \& $921 \quad$ Review, 21, 861-883.

922 Lorimor, H., Bock, K., Zalkind, E., Sheyman, A., \& Beard, R. (2008). Agreement and 923 attraction in Russian. Language and Cognitive Processes, 23, 769-799.

924 Marsden, E., Williams, J., \& Liu, X. (2013). Learning novel morphology: The role of 925 meaning and orientation of attention at initial exposure. Studies in Second Language

926 Acquisition, 35, $619-654$.

927 McCarthy, C. (2008). Morphological variability in the comprehension of agreement: an 928 argument for representation over computation. Second Language Research, 24, $929 \quad 459-486$.

930 McDonald, J. (2006). Beyond the critical period: Processing-based explanations for poor 931 grammaticality judgment performance by late second language learners. Journal of 932 Memory and Language, 55, 381-401. 
933 McDonald, J., Bock, K., \& Kelly, M. (1993). Word and world order: Semantic,

934 phonological, and metrical determinants of serial position. Cognitive Psychology, 25,

$935 \quad 188-230$.

936 MacDonald, M., Just, M., \& Carpenter, P. (1992). Working memory constraints on the

937 processing of syntactic ambiguity. Cognitive Psychology, 24, 56-98.

938 MacWhinney, B. (1998). Models of the emergence of language. Annual Review of

939 Psychology, 49, 199-227.

940 Martin, K. \& Ellis, N. (2012). The roles of phonological short-term memory and working

941 memory in L2 grammar and vocabulary learning. Studies in Second Language

$942 \quad$ Acquisition, 34, 379-413.

943 McWhorter, J. (2001). The world's simplest grammars are creole grammars. Linguistic

944 typology, 5(2), 125-166.

945 McWhorter, J. (2007). Language Interrupted: Signs of Non-native Acquisition in

946 Standard Language Grammars. Oxford University Press.

947 Melton, A. (1963). Implications of short-term memory for a general theory of

948 memory. Journal of Memory and Language, 2, 1-28. 
949 Miestamo, M. (2008). Grammatical complexity in a cross-linguistic perspective. In M.

950 Miestamo, K. Sinnemaki, \& F. Karlsson (Eds.), Language complexity: Typology,

951 contact, change (pp. 23 - 42). Amsterdam and Philadelphia: Benjamins.

952 Miyake, A., \& Friedman, N. (1998). Individual differences in second language

953 proficiency: Working memory as "language aptitude". In Healy, A., \& Bourne, L.

954 (eds.) Foreign Language Learning: Psycholinguistic Studies on Training and

955 Retention. Mahwah, NJ: Lawrence Erlbaum, 339-364.

956 Molinaro, N., Su, J., \& Carreiras, M. (2016). Stereotypes override grammar: Social 957 knowledge in sentence comprehension. Brain and Language, 155, 36-43.

958 Morgan-Short, K., Sanz, C., Steinhauer, K., \& Ullman, M. (2010). Second language related potential study. Language Learning, 60, 154-193.

961 Nakamura, D. (2012). Input skewedness, consistency, and order of frequent verbs in 962 frequency-driven second language construction learning: A replication and extension of Casenhiser and Goldberg (2005) to adult second language acquisition. IRAL, 50, $1-37$.

965 Norris, J., \& Ortega, L. (2000). Effectiveness of L2 instruction: A research synthesis and quantitative meta-analysis. Language Learning, 50, 417-528. 
967 Pallotti, G. (2015). A simple view of linguistic complexity. Second Language Research,

$968 \quad 31,117-134$.

969 Pienemann, M. (1989). Is language teachable? Psycholinguistic experiments and

$970 \quad$ hypotheses. Applied Linguistics, 10, 52-79.

971 Plunkett, K., \& Marchman, V. (1991). U-Shaped learning and frequency effects in a

972 muitilayered perceptron: Implications for child language acquisition. Cognition, 38,

$973 \quad 43-102$.

974 Presson, N., MacWhinney, B., \& Tokowicz, N. (2014). Learning grammatical gender:

975 The use of rules by novice learners. Applied Psycholinguistics, 35, 709-737.

976 Reali, F., \& Christiansen, M. (2009). Sequential learning and the interaction between

977 biological and linguistic adaptation in language evolution. Interaction Studies, 10, 5-

$978 \quad 30$.

979 Reber, A. (1989). Implicit learning and tacit knowledge. Journal of Experimental

980 Psychology: General 118, 219-235.

981 Rebuschat, P., \& Williams, J. (2012). Implicit and explicit knowledge in second language

982 acquisition. Applied Psycholinguistics, 33, 1-28. 
Robinson, P. (1996). Learning simple and complex second language rules under implicit, incidental, rule-search and instructed conditions. Studies in Second Language Acquisition, 18, 27-67.

Robinson, P. (2005). Cognitive abilities, chunk-strength, and frequency effects in implicit artificial grammar and incidental L2 learning: Replications of Reber, Walkenfeld, and Hernstadt (1991) and Knowlton, and Squire (1996) and their relevance for SLA. Studies in Second Language Acquisition, 27, 235-268.

990 Robinson, P. (2010). Implicit artificial grammar and incidental natural second language 991 learning: How comparable are they? Language Learning, 6 (2), 245-263.

992 Roehr, K. (2008). Linguistic and metalinguistic categories in second language learning. 993 Cognitive Linguistics, 19, 67-106.Rogers, J., Revesz, A., \& Rebuschat, P. (2015). $1-32$ by 12-month-old infants. Infancy, 4 (2), 273-284.

998 Sagarra, N. (2007). Online processing of gender agreement in low proficient English- 
1000 Sanchez L (Eds.) Romance linguistics 2006: Selected papers from the 36th

1001 Linguistic Symposium on Romance Languages. Amsterdam: John Benjamins, 240-

253.

1003 Sagarra, N. \& Herschensohn, J. (2010). The role of proficiency and working memory in

1004 gender and number agreement processing in L1 and L2 Spanish. Lingua, 120, 2022-

10052039.

1006 Sagarra, N., \& Herschensohn, J. (2012). Processing of gender and number agreement

1007 in late Spanish bilinguals. International Journal of Bilingualism, 17, 607-627.

1008 Shiffrin, R., \& Schneider, W. (1977). Controlled and automatic human information

1009 processing: II Perceptual learning, automatic attending and general theory.

$1010 \quad$ Psychological Review, 84, 127-190.

1011 Slobin, D. (1985). Crosslinguistic evidence for the language making capacity. In: D.

1012 Slobin (Eds.) The Crosslinguistic Study of Language Acquisition. Hillsdale, NJ:

$1013 \quad$ Erlbaum, 1157-1249.

1014 Spada, N., \& Tomita, Y. (2010). Interactions between type of instruction and type of

1015 language features: A meta-analysis. Language Learning, 60, 263-308. 
1016 Speciale, G., Ellis, N., \& Bywater, T. (2004). Phonological sequence learning and short-

1017 term store capacity determine second language vocabulary acquisition. Applied

$1018 \quad$ Psycholinguistics, 25, 293-321.

1019 Siyanova-Chanturia, A., Pesciarelli, F., \& Cacciari, C. (2012). The electrophysiological $1020 \quad$ underpinnings of processing gender stereotypes in language. PLoS One, 7 (12), 1$1021 \quad 11$.

1022 Tagarelli, K., Borges-Mota, M., \& Rebuschat, P. (2011). The role of WM in implicit and 1023 explicit language learning, 2061-2066.

1024 Tagarelli, K. M., Ruiz-Hernández, S., Vega, J. L. M., \& Rebuschat, P. (2016). Variability 1025 in second language learning: The roles of individual differences, learning conditions, 1026 and linguistic complexity. Studies in Second Language Acquisition, 38 (2), 293 $1027 \quad 316$.

1028 Taguchi, N. (2007). Chunk learning and the development of spoken discourse in a 1029 Japanese as a foreign language classroom. Language Teaching Research, 11, 433$1030 \quad 457$.

1031 Tanner, D., Nicol, J., \& Brehm, L. (2014). The time-course of feature interface in 1032 agreement comprehension: Multiple mechanisms and asymmetrical attraction. 1033 Journal of Memory and Language, 76, 195-215. 
1034 Thiessen, E., \& Saffran, J. (2003). When cues collide: Use of stress and statistical cues

1035 to word boundaries by 7-to 9-month-old infants. Developmental Psychology, 39 (4),

$1036 \quad 706-716$.

1037 Tomasello, M. (2000). The item-based nature of children's early syntactic development.

$1038 \quad$ Trends in Cognitive Sciences, 4, 156-163.

1039 Tomasello, M. (2008). Origins of Human Communication. Cambridge: The MIT Press.

1040 Unsworth, N., Heitz, R., Schrock, J., \& Engle, R. (2005). An automated version of the

1041 operation span task. Behavior Research Methods, 37, 498-505.

1042 Waters G, Caplan, D., \& Yampolsky, S. (2003). On-line syntactic processing under

1043 concurrent memory load. Psychonomic Bulletin and Review, 10, 88-95.

1044 Weitz, D., O’Shea, G., Zook, N., \& Needham, W. (2011). Working memory and

1045 sequence learning in the Hebb digits task: Awareness is predicted by individual

1046 differences in operation span. The American Journal of Psychology, 124 (1): 49-62.

1047 Williams, J. (2012). Working memory and SLA. In S. M. Gass \& A. Mackey (Eds.), The

1048 Routledge handbook of second language acquisition (pp. 427-441). New York, NY:

1049 Routledge. 
1050 Williams, J. \& Evans, J. (1998). What kind of focus and on which forms? In: Doughty C

1051 and Williams J (eds.) Focus on Form in Classroom Second Language Acquisition.

1052 Cambridge: Cambridge University Press, 139-155.

1053 Williams, J. \& Lovatt, P. (2003). Phonological memory and rule learning. Language

$1054 \quad$ Learning, 53, 67-121.

1055 Yang, J. \& Li, P. (2012) Brain networks of explicit and implicit learning. PLOSONE 7: 110569.

1057

1058

1059

1060

1061

1062

1063

1064

1065

1066 


\begin{tabular}{lll}
\hline Noun & Adjective & Preposition \\
\hline vedma - witch & krasniy - red & Idu k... - I am going towards \\
karlik- dwarf & jeltiy - yellow & Idu s... - I am going with \\
nevesta - bride & lisiy - bald & Idu ot... - I am going from \\
vdova - widow & maliy - small & \\
pojarnik - firefighter & \\
begun - runner &
\end{tabular}

1070

1071

1072

Training Sentences

1073 Masculine singular

1074 Eto seriy pojarnik/ This is a grey firefighter

1075 Idu k seromu pojarniku/ I am going towards the grey firefighter

1076 Idu s serim pojarnikom/ I am going with the grey firefighter

1077 Idu ot serogo pojarnika/ I am going away from the grey firefighter

1078

1079 Eto maliy karlik/ This is a small dwarf 
1080 Idu k malomu karliku/ I am going towards the small dwarf

1081 Idu s malim karlikom/ I am going with the small dwarf

1082 Idu ot malogo karlika / I am going away from the small dwarf

1083

1084 Eto jeltiy begun/ This is a yellow runner

1085 Idu $\mathrm{k}$ jeltomu begun/ I am going towards the yellow runner

1086 Idu s jeltim begunom/ I am going with the yellow runner

1087 Idu ot jeltogo beguna/ I am going away from the yellow runner

1088

1089 Eto yuniy shkolnik/ This is a young schoolboy

1090 Idu k yunomu shkolniku/ I am going towards the young schoolboy

1091 Idu s yunim shkolnikom/ I am going with the young schoolboy

1092 Idu ot yunogo shkolnika/ I am going away from the young schoolboy

1093

1094 Eto lisiy letchik/ This is a bald pilot

1095 Idu k lisomu letchiku/ I am going towards the bald pilot

1096 Idu s lisim letchikom/ I am going with the bald pilot 
1097 Idu ot lisogo letchika/ I am going away from the bald pilot

1098

1099 Eto temniy fokusnik/ This is a brunette conjurer

1100 Idu k temnomu fokusniku/ I am going towards the brunette conjurer

1101 Idu s temnim fokusnikom/ I am going with the brunette conjurer

1102 Idu ot temnogo fokusnika/ I am going away from the brunette conjurer

1104 Eto krupniy ohotnik/ This is a big hunter

1105 Idu k krupnomu ohotniku/ I am going towards the big hunter

1106 Idu s krupnim ohotnikom/ I am going with the big hunter

1107 Idu ot krupnogo ohotnika/ I am going away from the big hunter

1109 Masculine plural

1110 Eto serie pojarniki/ These are grey firefighters

1111 Idu k serim pojarnikam/ I am going towards the grey firefighters

1112 Idu s serimi pojarnikami/ I am going with the grey firefighters

1113 Idu ot serih pojarnikov/ I am going away from the grey firefighters 
1115 Eto malie karliki/ These are small dwarves

1116 Idu k malim karlikam/ I am going towards the small dwarves

1117 Idu s malimi karlikami/ I am going with the small dwarves

1118 Idu ot malih karlikov/ I am going away from the small dwarves

1120 Eto jeltie beguni/ These are yellow runners

1121 Idu $\mathrm{k}$ jeltim begunam/ I am going towards the yellow runners

1122 Idu s jeltimi begnami/ I am going with the yellow runners

1123 Idu ot jeltih begunov/ I am going away from the yellow runners

1126 Eto yunie shkolniki/ These are young schoolboys

1127 Idu k yunim shkolnikam/ I am going towards the young schoolboys

1128 Idu s yunimi shkolnikami/ I am going with the young schoolboys

1129 Idu ot yunih shkolnikov/ I am going away from the young schoolboys

1131 Eto lisie letchiki/ These are a bald pilots

1132 Idu $\mathrm{k}$ lisim letchikam/ I am going towards the bald pilots 
1133 Idu s lisimi letchikami/ I am going with the bald pilots

1134 Idu ot lisih letchikov/ I am going away from the bald pilots

1136 Eto temnie fokusniki/ These are brunette conjurers

1137 Idu k temnim fokusnikam/ I am going towards the brunette conjurers

1138 Idu s temnimi fokusnikami/ I am going with the brunette conjurers

1139 Idu ot temnih fokusnikov/ I am going away from the brunette conjurers

1141 Eto krupnie ohotniki/ These are big hunters

1142 Idu k krpnim ohotnikam/ I am going towards the big hunters

1143 Idu s krpnimi ohotnikami/ I am going with the big hunters

1144 Idu ot krpnih ohotnikov/ I am going away from the big hunters

\section{Feminine singular}

1147 Eto grustnaya vdova/ This is a sad widow

1148 Idu k grustnoy vdove/ I am going towards the sad widow

1149 Idu s grustnoy vdovoy/ I am going with the sad widow 
1150 Idu ot grustnoy vdovi/ I am going away from the sad widow

1152 Eto belaya nevesta/ This is an white bride

1153 Idu k beloy neveste/ I am going towards the white bride

1154 Idu s beloy nevestoy/ I am going with the white bride

1155 Idu ot beloy nevesti/ I am going away from the white bride

1157 Eto hudaya stryapuha/ This is a thin cook

1158 Idu k hudoy stryapuhe/ I am going towards the thin cook

1159 Idu s hudoy stryapuhoy/ I am going with the thin cook

1160 Idu ot hudoy stryapuhi/ I am going away from the thin cook

1162 Eto svetlaya podruga/ This is a blonde friend

1163 Idu k svetloy podruge/ I am going towards the blonde friend

1164 Idu s svetloy podrugoy/ I am going with the blonde friend

1165 Idu ot svetloy podrugi/ I am going away from the blonde friend 
1167 Eto tolstaya tkachiha/ This is a fat weaver

1168 Idu k tolstoy tkachihe/ I am going towards the fat weaver

1169 Idu s tolstoy tkachihoy/ I am going with the fat weaver

1170 Idu ot tolstoy tkachihi/ I am going away from the fat weaver

1172 Eto staraya portniha/ This is an old dressmaker

1173 Idu k staroy portnihe/ I am going towards the old dressmaker

1174 Idu s staroy portnihoy/ I am going with the old dressmaker

1175 Idu ot staroy portnihi/ I am going away from the old dressmaker

1177 Eto chernaya plovchiha/ This is a black swimmer

1178 Idu k chernoy plovchihe/ I am going towards the black swimmer

1179 Idu s chernoy plovchihoy/ I am going with the black swimmer

1180 Idu ot chernoy plovchihe/ I am going away from the black swimmer

\section{$1182 \quad$ Feminine plural}

1183 Eto grustnie vdovi/ These are sad widows 
1184 Idu k grustnim vdovam/ I am going towards the sad widows

1185 Idu s grustnimi vdovami/ I am going with the sad widows

1186 Idu ot grustnih vdov/ I am going away from the sad widows

1187

1188

1189 Eto belieie nevesti/ These are white brides

1190 Idu k beieim nevestam/ I am going towards the white brides

1191 Idu s belimii nevestami/ I am going with the white brides

1192 Iduu ot belih nevest/ I am going away from the white brides

1194 Eto hudie stryapuhi/ These are thin cooks

1195 Idu k hudim stryapuham/ I am going towards the thin cooks

1196 Idu s hudimi stryapuhami/ I am going with the thin cooks

1197 Idu ot hudih stryapuh/ I am going away from the thin cooks

1198

1199 Eto svetlie podrugi/ These are blonde friends

1200 Idu k svetlim podrugam/ I am going towards the blonde friends

1201 Idu s svetlimi podrugami/ I am going with the blonde friends

1202 Iduu ot svetlih podrug/ I am going away from the blonde friends 
1204 Eto tolstie tkachihi/ These are fat weavers

1205 Idu k tolstim tkachiham/ I am going towards the fat weavers

1206 Idu s tolstimi tkachihami/ I am going with the fat weavers

1207 Idu ot tolstih tkachih/ I am going away from the fat weavers

1209 Eto starie portnihi/ These are old dressmakers

1210 Idu k starim portniham/ I am going towards the old dressmakers

1211 Idu s starimi portnihami/ I am going with the old dressmakers

1212 Idu ot starih portnih/ I am going away from the old dressmakers

1215 Eto chernie plovchihi/ These are black swimmers

1216 Idu k chernim plovchiham/ I am going towards the black swimmers

1217 Idu s cherntimi plovchihami/ I am going with the black swimmers

1218 Idu ot chernih plovchih/ I am going away from the black swimmers 
1222

1223

1224

1225

1226

1227

1228

1229

1230

1231

1232

1233

1234

1235

1236

1237

1238

1239

1240

1241

1242

1243

1244

1245

Inflectional Paradigm in Russian for the Adjective and the Noun According to Number, Gender and Case

\begin{tabular}{|c|c|c|c|c|c|c|c|c|}
\hline \multirow[t]{3}{*}{ Case } & \multicolumn{4}{|c|}{ Masculine } & \multicolumn{4}{|c|}{ Feminine } \\
\hline & \multicolumn{2}{|c|}{ Singular } & \multicolumn{2}{|c|}{ Plural } & \multicolumn{2}{|c|}{ Singular } & \multicolumn{2}{|c|}{ Plural } \\
\hline & Adj. & $\mathrm{N}$ & Adj. & $\mathrm{N}$ & Adj. & $\mathrm{N}$ & Adj. & $\mathrm{N}$ \\
\hline Nominative & -iy & $\varnothing$ & -ie & $-\mathrm{i}$ & -aya & $-a$ & -ie & $-\mathrm{i}$ \\
\hline Dative & -omu & $-\mathrm{u}$ & -im & $-a m$ & -oy & $-e$ & -im & -am \\
\hline Instrumental & -im & -om & -imi & -ami & -oy & -oy & -imi & -ami \\
\hline Genitive & -ogo & $-\mathrm{a}$ & $-\mathrm{ih}$ & $-\mathrm{OV}$ & -oy & $-\mathrm{i}$ & $-\mathrm{ih}$ & $\varnothing$ \\
\hline
\end{tabular}

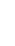

Table 1 
Table 2

1247 Examples of Training Sentences Presented to Participants

\begin{tabular}{|c|c|c|}
\hline Case & Masculine singular & Masculine plural \\
\hline \multirow[t]{2}{*}{ Nominative } & Eto maliy karlik- This is a small dwarf & Eto malie karliki- These are small dwarves \\
\hline & $\begin{array}{lll}\text { Eto } & \text { mal-iy } & \text { karlik- } \emptyset \\
\text { This } \emptyset \text {-cop } & \text { small-M.NOM.SG } & \text { dwarf-M.NOM.SG }\end{array}$ & $\begin{array}{lll}\text { Eto } & \text { mal-ie } & k a r l i k-i \\
\text { These } \emptyset \text {-cop } & \text { small-M.NOM.PL } & \text { dwarf-M.NOM.PL }\end{array}$ \\
\hline \multirow[t]{2}{*}{ Dative } & $\begin{array}{l}\text { Idu k malomu karliku- I am going towards } \\
\text { the small dwarf }\end{array}$ & $\begin{array}{l}\text { Idu k malim karlikam- I am going towards } \\
\text { the small dwarves }\end{array}$ \\
\hline & $\begin{array}{llll}I d u & k & \text { mal-omu } & \text { karlik-- } u \\
\text { I am going } & \text { towards } & \text { small-M.DAT.SG } & \text { dwarf- } \\
\text { M.DAT.SG } & & \end{array}$ & $\begin{array}{llll}\text { Idu } & k & \text { mal-im } & \text { karlik-am } \\
\text { I am going } & \text { towards } & \text { small-M.DAT.PL } & \text { dwarf- } \\
\text { M.DAT.PL } & & & \end{array}$ \\
\hline \multirow[t]{2}{*}{ Instrumental } & $\begin{array}{l}\text { Idu s malim karlikom- I am going with the } \\
\text { small dwarf }\end{array}$ & $\begin{array}{l}\text { Idu s malimi karlikami- I am going with the } \\
\text { small dwarves }\end{array}$ \\
\hline & $\begin{array}{llll}\text { Idu } & s & \text { mal-im } & \text { karlik-om } \\
\text { I am going } & \text { with } & \text { small-M.INST.SG } & \text { dwarf- } \\
\text { M.INST.SG } & & \end{array}$ & $\begin{array}{lcll}\text { Idu } & s & \text { mal-imi } & \text { karlik--ami } \\
\text { I am going } & \text { with } & \text { small-M.INST.PL } & \text { dwarf- } \\
\text { M.INST.PL } & & \end{array}$ \\
\hline \multirow[t]{2}{*}{ Genitive } & $\begin{array}{l}\text { Idu ot malogo karlika- I am going away } \\
\text { from the small dwarf }\end{array}$ & $\begin{array}{l}\text { Idu ot malih karlikov- I am going away from } \\
\text { the small dwarves }\end{array}$ \\
\hline & $\begin{array}{llll}I d u & \text { ot } & \text { mal-ogo } & \text { karlik-a } \\
\text { I am going } & \text { away from } & \text { small-M.GEN.SG } & \begin{array}{l}\text { dwarf- } \\
\text { M.GEN.SG }\end{array}\end{array}$ & $\begin{array}{llll}\text { Idu } & \text { ot } & \text { mal-ih } & \text { karlik-ov } \\
\text { I am going } & \text { away from } & \text { small-M.GEN.PL } & \text { dwarf- } \\
\text { M.GEN.PL } & & & \end{array}$ \\
\hline
\end{tabular}


1262 Table 3

1263 Distribution of Types and Tokens during Training

\begin{tabular}{|c|c|c|c|c|c|c|}
\hline $\begin{array}{l}\text { Incidenal learning } \\
\text { condition }\end{array}$ & $\begin{array}{l}\text { Feminine } \\
\text { gender }\end{array}$ & $\begin{array}{l}\text { Masculine } \\
\text { gender }\end{array}$ & Case & Number & Repeated & $\begin{array}{l}\mathrm{N} \text { of } \\
\text { trials }\end{array}$ \\
\hline $\begin{array}{l}\text { high type/low token } \\
\text { frequency }\end{array}$ & 7 stories & 7 stories & 4 cases & $\begin{array}{l}2 \\
\text { (singular, } \\
\text { plural) }\end{array}$ & 3 times. & 336 \\
\hline $\begin{array}{l}\text { low type/high token } \\
\text { frequency }\end{array}$ & 3 stories & 3 stories & 4 cases & $\begin{array}{l}2 \\
\text { (singular, } \\
\text { plural) }\end{array}$ & 7 times & 336 \\
\hline $\begin{array}{l}\text { low type/low token } \\
\text { frequency }\end{array}$ & 3 stories & 3 stories & 4 cases & $\begin{array}{l}2 \\
\text { (singular, } \\
\text { plural) }\end{array}$ & 3 times & 144 \\
\hline
\end{tabular}

1264

1265

1266

1267

1268

1269

1270

1271

1272

1273

1274

1275

1276

1277

1278

1279

1280 
1282 Table 4

1283 Model Selection

\begin{tabular}{lccc}
\hline Predictor & AIC & BIC & Pr (>Chisq) \\
\hline Condition & 1536.88 & 1553.16 & $p<.001$ \\
Operation Span & 1536.37 & 1558.07 & .113 \\
Block (old vs. new) & 1537.30 & 1564.43 & .748 \\
Number & 1539.30 & 1571.86 & .810 \\
Gender & 1542.87 & 1586.28 & .133 \\
Case & 1538.57 & 1598.26 & .062 \\
Condition x block & 1536.52 & 1607.07 & .724 \\
Condition x number & 1540.01 & 1621.41 & .903 \\
Number x gender & 1543.82 & 1636.07 & .272 \\
\hline
\end{tabular}

1284

Full model: Condition, Operation Span, Block, Number, Gender, Case.

1285 Condition X Block, Condition X Number, Number X Gender, Block X Number

1286

1287

1288

1289

1290

1291

1292

1293

1294

1295 
1297 Table 5

1298 Descriptive Statistics for Participants' Accuracy and WM Scores

\begin{tabular}{lcccccc}
\hline \multirow{2}{*}{ Condition } & \multicolumn{2}{c}{ WM } & \multicolumn{2}{c}{ Comprehension } & \multicolumn{2}{c}{ Production } \\
\cline { 2 - 7 } & $M$ & $S D$ & $M$ & $S D$ & $M$ & $S D$ \\
\hline High type/low token & 51.70 & 14.22 & 25.05 & 1.64 & 2.40 & 2.78 \\
Low type/high token & 59.90 & 13.67 & 23.65 & 3.23 & 3.90 & 4.17 \\
Low type/low token & 60.75 & 10.52 & 19.75 & 7.77 & 2.75 & 2.95
\end{tabular}

$1299 \quad$ Note: $M$ and $S D$ represent raw scores

1300

1301

1302

1303

1304

1305

1306

1307

1308

1309

1310

1311

1312

1313

1314

1315

1316

1317 
1319 Table 6

1320 Explicit Learning Condition vs. Incidental Learning Conditions for Comprehension

\begin{tabular}{|c|c|c|c|c|c|c|}
\hline \multirow[b]{2}{*}{ Condition } & \multicolumn{3}{|c|}{ Comprehension accuracy } & \multicolumn{3}{|c|}{ Comprehension $R T \mathrm{~s}$} \\
\hline & Std. Error & $\begin{array}{c}\text { Wald } \\
\mathrm{z}\end{array}$ & $p$ value & Std. Error & $\mathrm{t}$ value & $p$ value \\
\hline $\begin{array}{l}\text { High type/low token } \\
\text { frequency }\end{array}$ & 1.76 & 3.30 & $<.001 * * *$ & 33.25 & 0.67 & 0.51 \\
\hline $\begin{array}{l}\text { Low type/high token } \\
\text { frequency }\end{array}$ & 1.60 & 0.74 & 0.46 & 33.26 & 0.94 & 0.34 \\
\hline $\begin{array}{l}\text { Low type/low token } \\
\text { frequency }\end{array}$ & 1.45 & -4.64 & $<.001 * * *$ & 33.35 & -3.24 & $0.001 * *$ \\
\hline Block (old vs. new) & 4.35 & 0.34 & 0.66 & 88.43 & 0.25 & 0.80 \\
\hline Operation span & 4.14 & 0.29 & 0.77 & 0.86 & 1.56 & 0.12 \\
\hline
\end{tabular}

1321

1322

1323

1324

1325

1326

1327

1328

1329

1330

1331

1332

1333

1334

1335 
1337 Table 7

1338 Explicit vs. Incidental Learning for Production

Production accuracy

\begin{tabular}{lccc}
\hline Condition & Std. Error & $\begin{array}{c}\text { Wald } \\
\mathrm{Z}\end{array}$ & $p$ value \\
\hline High type/low token frequency & 0.19 & -5.53 & $<.001^{* * *}$ \\
Low type/high token frequency & 0.16 & -3.50 & $<.001 * * *$ \\
Low type/low token frequency & 0.17 & -5.43 & $<.001^{* * *}$ \\
Block (old vs. new) & 0.40 & -1.94 & $0.05^{*}$ \\
Operation span & 0.00 & 2.16 & $0.03 *$ \\
\hline
\end{tabular}

1339

1340

1341

1342

1343

1344

1345

1346

1347

1348

1349

1350

1351

1352

1353

1354

1355

1356 


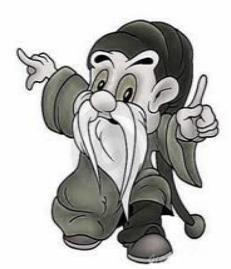

Eto maliy karlik

$1358 \quad 1)$

1359

1360

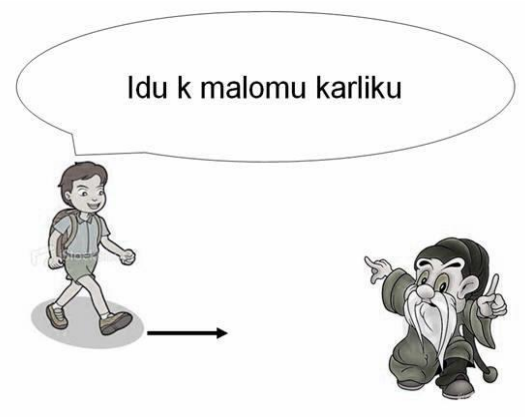

$1361 \quad 3)$

1362

1363

1364

1365

5)

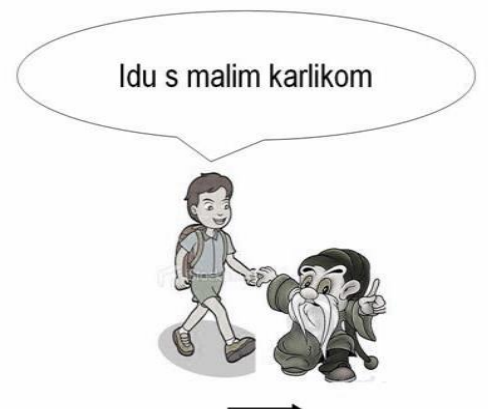

1366

1367

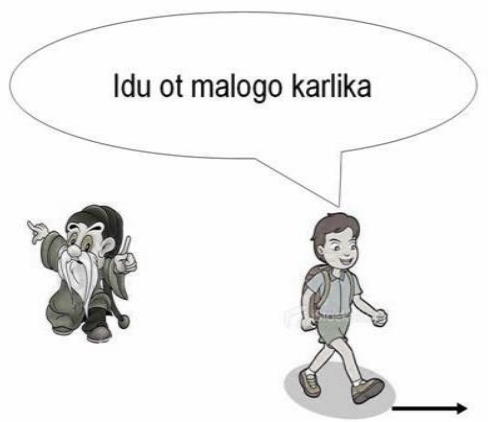

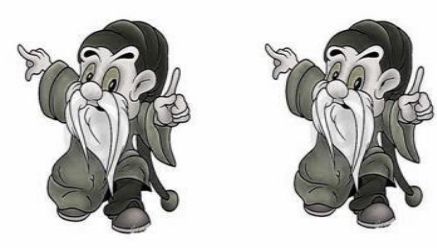

Eto malie karliki

2)

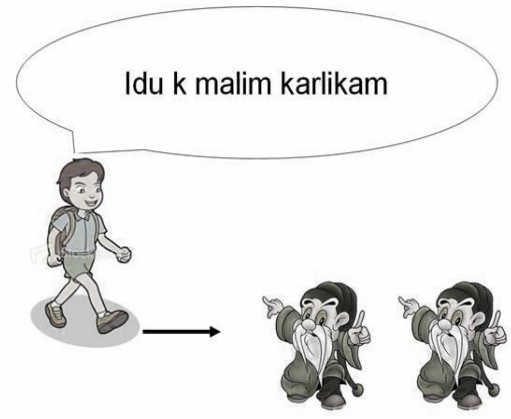

4)

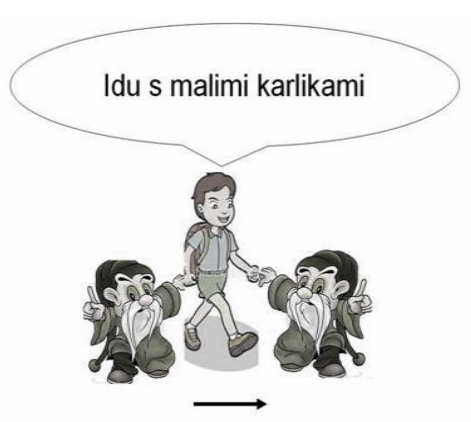

6)

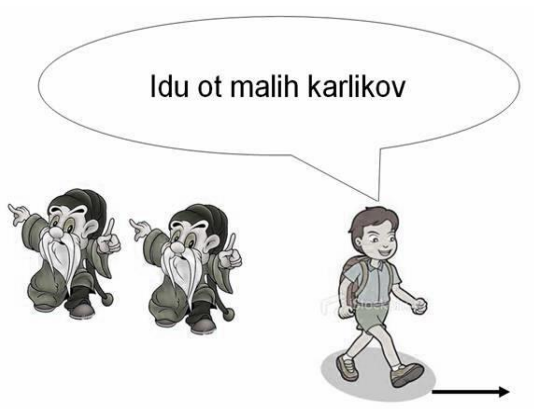

8)

Figure 1. Example of the set of trials presented to the participants during training 


\section{Accuracy in Comprehension}

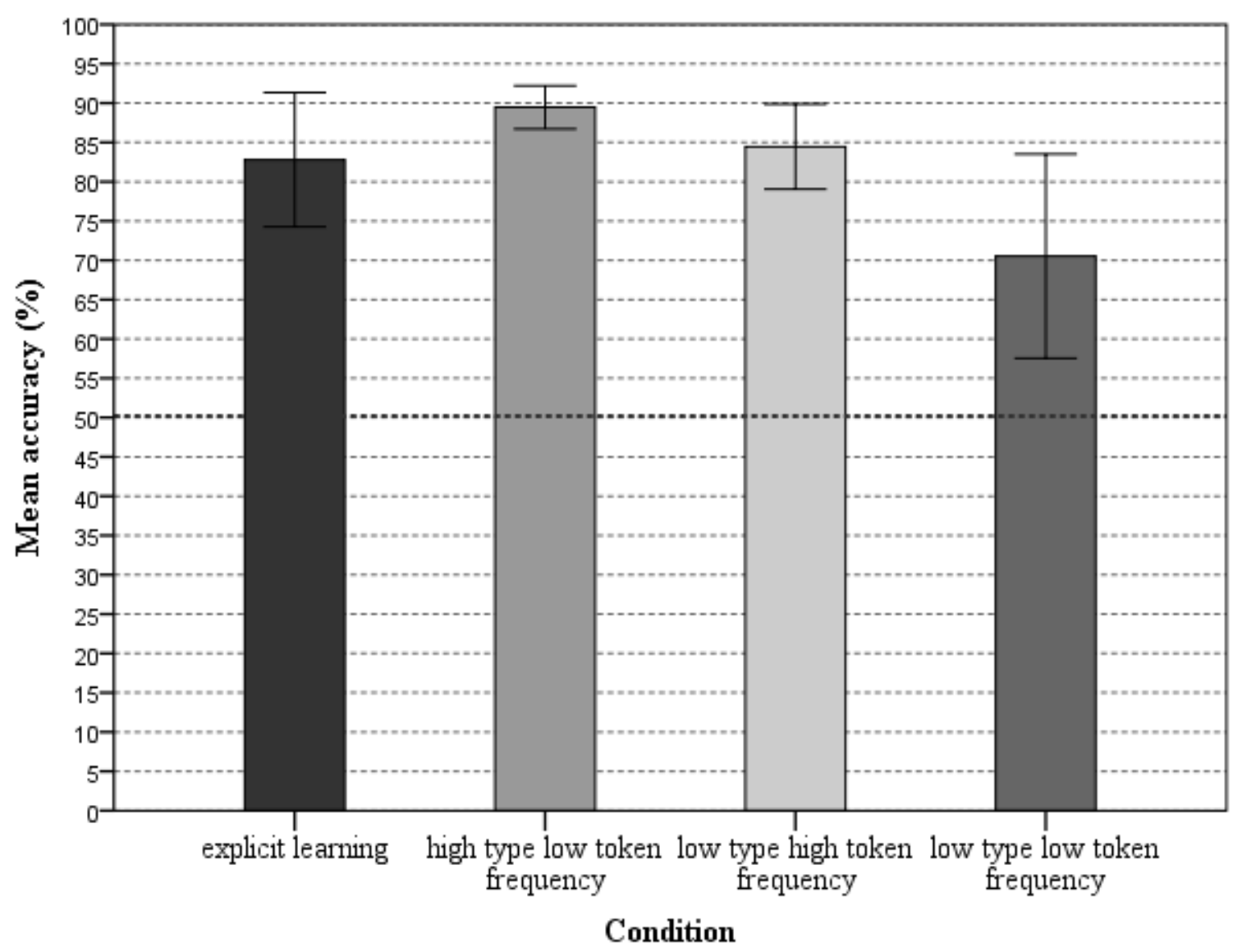

Error Bars: 95\% CI

1377 Figure 2. Accuracy performance by percentages of participants in the explicit learning and 1378 incidental learning conditions on the recognition task 


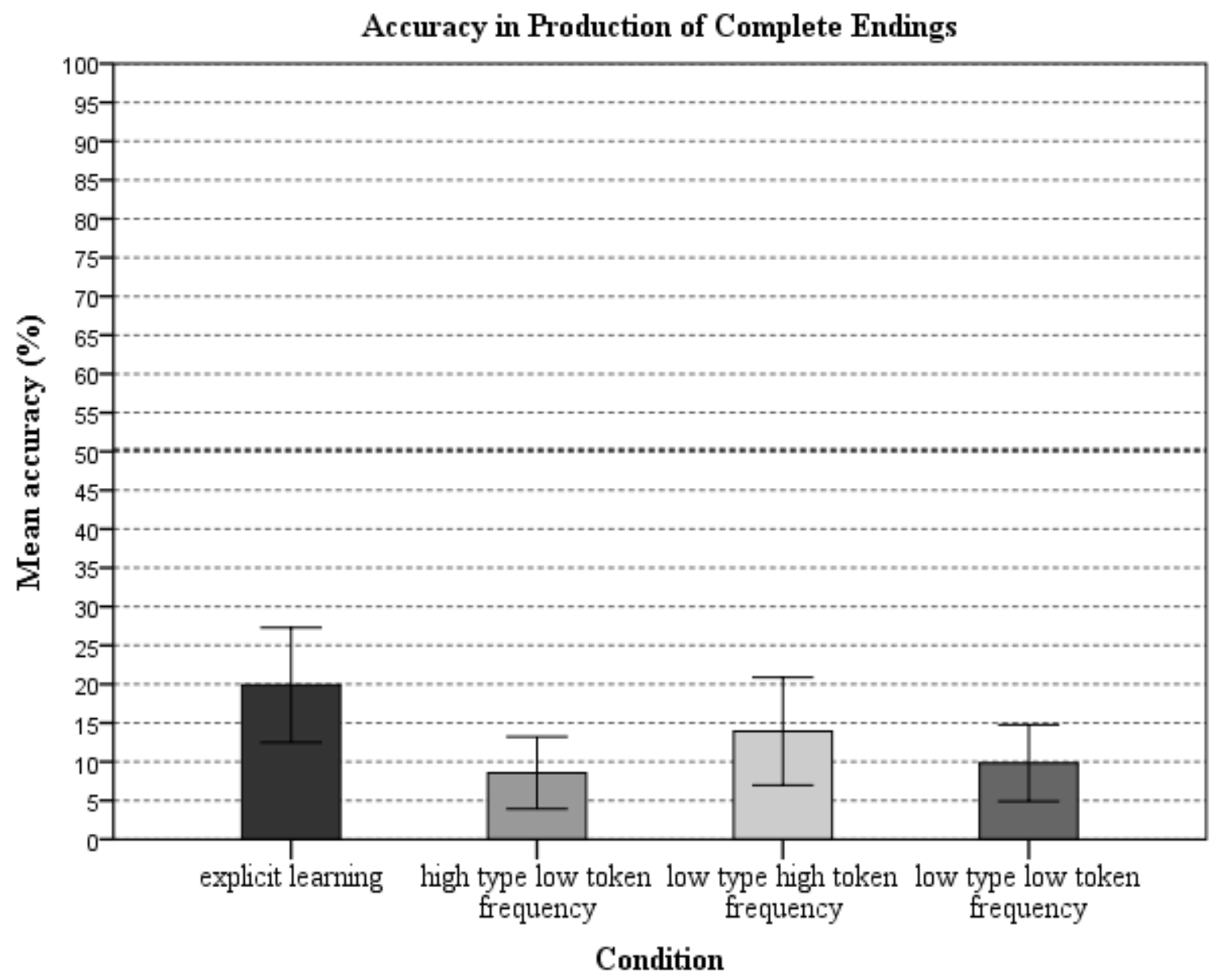

Error Bars: $95 \%$ CI

1391 Figure 3. Accuracy in production of endings (\%) by participants in the explicit learning and 1392 incidental learning conditions on the fill-in-the-blank task 


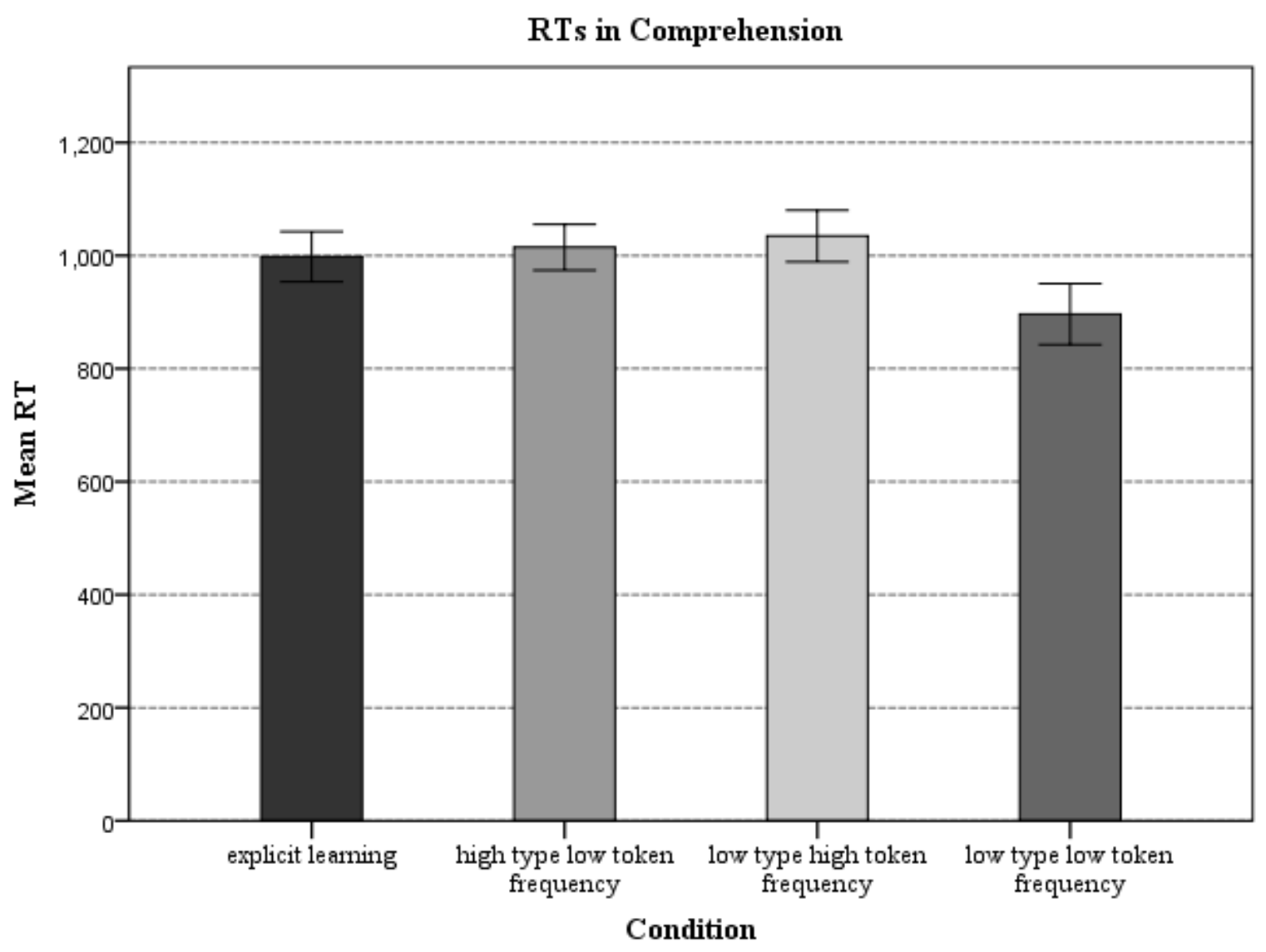

Error Bars: $95 \% \mathrm{Cl}$

1405 Figure 4. Mean RTs of participants in the explicit learning and incidental learning conditions on 1406 the recognition task

1407 